\title{
WRITING INTO DESIGN: AN EMBEDDED WRITING COURSE FOR ARCHITECTURAL STUDIES
}

\author{
K. Manià* \\ Academic Development Unit \\ e-mail: kirbymania@gmail.com
}

\section{A. Janse van Rensburg*}

School of Architecture and Planning

e-mail: Ariane.JanseVanRensburg@wits.ac.za

\section{R. Bird*}

Visiting Associate Professor of Architecture at

The University of Johannesburg

Johannesburg, South Africa

e-mail: rbird@post.harvard.edu

*University of the Witwatersrand

Johannesburg, South Africa

\section{ABSTRACT}

Architects must be able to express their ideas clearly to communicate their designs. At the same time, graduate professional degree programs demand advanced critical literacy and academic writing skills. Competence in this domain for high school graduates in South Africa often falls short of the expected proficiencies of first-year students at the tertiary level. To address this gap, an embedded writing course was integrated into the first-year Design Studio and History of Architecture course. This intervention adopted the approaches provided by writing-intensive pedagogy, successfully improving students' written expression, and their ability to engage with their architectural studies in deeper and more critical ways.

Keywords: writing intensive pedagogy, embedded writing course, architectural studies, design, history

\section{INTRODUCTION}

This article addresses the question: What is the value of teaching first-year undergraduate students how to engage with critical thinking through writing in unison with Design Studio and Architectural History in South African schools of architecture? While this case study is restricted to the authors' input in developing the curriculum and teaching at the School of Architecture and Planning (hereafter, SoAP) at the University of the Witwatersrand (hereafter, 
Wits), teaching intensive writing as an integral part of the first-year architectural course resulted in several positive outcomes, which may also be applicable to other architecture programs, most notably in increasing the likelihood that students, especially those at risk of failing, will continue to advance in and eventually complete their professional degrees.

Given the daily timetable constraints, which are quite rigid in South African universities, integrating a dedicated Writing course, taught by Kirby Mania, within the structures of the existing first-year History of Architecture course, taught by Randall Bird, and the Design Studio, led by Ariane Janse van Rensburg, made the most sense. The Design Studio, which should integrate knowledge from all other courses, offers the most student contact time and flexibility. This embedded approach to writing promised the benefit of 'breaking down silos' in terms of the hermetic and non-symbiotic ways in which students tend to think about their learning across separate, interdisciplinary courses.

The initial idea for the Writing course was modelled on English Composition for firstyear undergraduates, which is mandatory at most American universities. Ideally, intensive writing courses at early stages in the undergraduate years serve as a foundation for a liberal arts education by introducing approaches to writing for students having a wide range of academic interests and career goals, and coming from a variety of social and economic backgrounds.

The SoAP embedded Writing course takes place during the first semester of the first-year programme. The curriculum encompasses material that lends itself to close reading and literary analysis, creative exercises and critical argumentation. The objective is to develop students' reading and writing skills to enhance critical literacy, abstract thought, and argument construction. Embedded-writing draws upon a diverse array of multidisciplinary texts and media that lend themselves to literary and textual study, bringing in voices and perspectives from different social and cultural contexts.

\section{CONTEXT}

In South African architectural education, English language competency is assumed, and writing skills are traditionally not taught in a separate course. In the USA, the architecture curriculum often includes a writing course, aimed at developing argumentative and expository writing in order to present the logic of design arguments (Hoag and Smit 2009, 93). In the South African environment, students come from increasingly diverse backgrounds in terms of schooling, economic class, urban exposure, and culture, which are no longer determined by race alone. This diversity extends to aspirations, approaches to learning and authority, modes of expression and understandings of community and place. In a survey of Bachelor of Architecture (BAS) 
students' experience of the Design course, fifteen percent of the respondents, who represented a diverse cross-section of southern African architecture students, reported having had no prior exposure to architecture, which included not having viewed architecture on the Internet before.

Many students find the gap between secondary school and learning how to design and think like an architect 'gargantuan' (Janse van Rensburg 2012), not in terms of knowledge, but in terms of the type of critical engagement that is expected from them in a tertiary educational environment. This is a common phenomenon in the greater African context (Olweny 2013). South African secondary school education generally operates on the lower levels of Bloom's taxonomy of learning ${ }^{1}$ (Bloom et al. 1956), leaving students with the impression that there is only one definitive answer for any given problem. In specific sub-cultures where this is combined with strong societal traditions of respect for authority, and an aversion to questioning elders' opinions, these conditions do not lend themselves to the development of critical thinking or independent learning skills.

In these contexts, the immediate priority in first-year teaching is to establish a studio climate that facilitates peer discussion and critical, creative investigation in order to develop a growing understanding of the nature of design within the broader South African context. Since reading and writing assignments draw on skills acquired in secondary school, written tasks become an approachable vehicle by which critical thinking and conversations about architecture can begin to take place, paving the way for a growing contextual understanding of the feedback that occurs in the design critique.

The majority of South African architecture students receive their secondary education through the medium of English and adequately pass the essay-writing component of the admissions exercise. However, for many of them, English is not their first language, and comprehension of abstract discourse is often more difficult than concrete expression. A Wits student described this experience as: 'Here you are struggling to conceptualise what is being delivered in the lecture and catch each and every English word. That itself is a challenge to you' (Janse van Rensburg 2012). Among the students who claimed to be first-language English speakers in a questionnaire given to Wits first-year BAS students from 2008 to 2011, roughly half reported some or even extreme difficulty in understanding written project briefs. An excellent student commented: 'The briefs were always fully understandable, however their deeper meaning wasn’t always apparent to the deer-in-the-headlights first year' (Janse van Rensburg 2012). In the majority of cases, this indicates unfamiliarity with deep and critical reading as much as a challenge in decoding meaning of an academic architectural register. Ten percent of the respondents indicated that they 'did not understand at all', while describing 
themselves as well-prepared for the course in terms of their command of English (Janse van Rensburg 2012).

Several students remarked that it took them more than a year to understand architectural terminology and concepts accurately (Janse van Rensburg 2012), which meant that they had often misinterpreted assignment instructions as well as lecturer-provided feedback and critique. City et al. state that the first step in learning is to develop a common language in which to describe and have discussions within the discipline (City et al. 2009). Although this is inherent to the acculturation process linked to any discipline, in Architecture, which is a form of cultural expression, it is further compounded by diverse spatial understandings. One student remarked that, 'Often concepts like "spatial quality”, “feelings of a space”, “scale” etc. were difficult to understand in architectural terms as they often mean very different things in our daily lives' (Janse van Rensburg 2012). Comments such as these, indicated the need to bring about clarity and a sense of consensus on the range of meanings encompassed by the field. One of the ways in which this was addressed was by introducing architecturally inclined reading, writing, and discussion into the mainstream Design and History curricula.

As evidenced by the provided student response, place and space have diverse and unique meanings in different cultural contexts, making it important to look critically at cultural context in terms of Bourdieu's theories on cultural reproduction ${ }^{2}$ (Bourdieu 1977; Bourdieu and Passeron 1990). In Sue Clegg's insightful sociological critique of tertiary education, she examines the role of cultural capital and postulates that educators only deliver on the promise of educational empowerment if the curriculum cultivates the formation of a student's intellectual identity (Clegg 2011). Concurrently, there is a need to equip architectural professionals with the ability to express themselves in a dominant discourse, both graphically and verbally.

Hilary Janks critically examines the power of language in Literacy and Power (Janks 2010), based on the premise that simply being literate does not give a student access to the habitus of academia. There are dominant ways of writing that are recognised in the habitus, that have more power and give greater access, because they constitute cultural capital. Orientating a student towards access would mean teaching her how to use dominant forms of expression that would be taken seriously. Orientating students towards diversity embraces calls for decolonising the academy by encouraging them to pursue individuated avenues towards self-expression. The 'access paradox' refers to the process by which a student is taught to use a dominant form of expression that grants access to the disciplinary register, but may involve her losing her own individual voice. The aim of empowering education is to promote both 
access and diversity learning, so as to avoid the pitfalls associated with the access paradox. ${ }^{3}$

In literacy pedagogy, the term for this is a 'design orientation', which selects ways of expression from any available source, creating new meanings through innovative combinations. This is described as ‘transformation and reconstruction' (Janks 2010). This approach is both academically and socially empowering in the South African context, which is still affected by deep-seated legacies of internalised dominance and oppression ${ }^{4}$ (Freire 1990). Students from non-dominant cultures often commence the course with the assumption that dominant northernhemisphere approaches are preferred, expressing aspirations to become designers of this ilk, trying to prove that they belong in an environment in which they do not feel entirely secure or accepted. This is evidenced by applicants' comments in Wits BAS admission interviews, confirmed by the CHE case study on Wits (CHE 2010), and may account for the fact that the students who found assignment briefs most difficult to understand described themselves as entirely proficient in English (Janse van Rensburg 2012).

The ability to express oneself compellingly allows for creative engagement across different disciplines. The development of critical thinking through writing has value that is directly relatable and transferable to Design and then eventually to the practice of architecture.

\section{'WRITING AS THINKING' PEDAGOGY}

A symbiotic relationship exists between writing, thinking, and the communication of design. Nora Wendl, in emphasizing the professional and educational correspondence between writing and architecture, states that 'Architects write ... to proliferate their practice, to communicate, and to make portable their concepts and ideas and projects' (Wendl 2009, 263). Similarly, Donald Schön writes that '... drawing and talking are parallel ways of designing and together make up ... the language of designing' (Schön 1983, 80).

Janet Emig in her paper 'Writing as a mode of thought' (Emig 1977) puts forward an argument that shores up the formative and pedagogical link between writing and thinking. She claims that writing constitutes a unique mode of learning, which as a practice 'corresponds to certain powerful learning strategies' (Emig 1977, 122). The coupled dynamism of writing as both a process and a product is what makes it such an effective learning strategy. Unlike the other three types of 'languaging processes' (listening, talking, and reading), writing involves the 'originating and creating [of] a unique verbal construct that is graphically recorded' (Emig 1977, 122, 123). Unlike talking, writing needs to provide its own context and speak to an absent audience, and since it is a slower activity than speech, it boasts a 'connective' and 'selfreviewing' quality (Emig 1977, 123). In other words, not only does writing need to be more 
deliberate and detailed than talking - clearly delineating context and audience in the process the written medium, being a recorded form, also allows one to re-read what has been written and then revise accordingly to ensure that what is represented is logical and sequentially rendered. In this way, writing is a more 'committed' and 'responsible' act than speech (Emig 1977, 127). Emig drives this point home as follows: 'Because writing is often our representation of the world made visible, embodying both process and product, writing is more readily a form and source of learning than talking' (Emig 1977, 124). Writing, in generating the synergistic activity of eye, brain, and hand, brings together the three learning stages outlined by Jerome Bruner, namely enactive, where one learns 'by doing' (here, generally, the hand is instrumental in actualising this learning process), iconic where learning takes place by depicting something via an image (here, the eye plays an important role) and symbolic, where one learns by restating something in words (here, the brain dominates in this type of learning) (Emig 1977, 124). Emig postulates that '[i]f the most efficacious learning occurs when learning is reinforced, then writing through its inherent re-inforcing cycle involving hand, eye, and brain marks a uniquely powerful multi-representational mode for learning’ (Emig 1977, 124-125). Writing represents an embodied and 'self-rhythmed' personal learning practice (Emig 1977, 126).

In 'Writing as thinking', Richard Menary expands on the dynamic, multimodal, and embodied nature of writing. Menary posits that written sentences are in fact 'vehicles of thought', subject to external manipulation and reworking. Being products of the cognitive process, they are yet another example of 'thinking in action' (Menary 2007, 622). Cognitive integration thus takes place as a result of the confluence between neural, bodily, and manipulative processes (i.e. the manipulation of external vehicles of thought, e.g. written sentences and mathematical formulae). As a result, writing is deemed a hybrid mental act, and by virtue of its manifestation as a representational and externalized mode of thought, it provides storage outside of one’s own internal memories (Menary 2007). In writing down one's thoughts, one is afforded the opportunity to restructure, revise, re-word, and re-draft what has already been written. Manipulating written vehicles not only allows one to make meaning clearer, but also further enables abstract thinking (Menary 2007).

Thus, the activity of writing equips its author with a physical product, what we can call recorded and externalised thought, which can then be revised, refined, or amplified. In this way, it is vital for students to appreciate that 'writing as a process' means that one's externalized thoughts are drafted, recomposed and reworked, in multiple versions before being able to arrive at a final product. That is why, for any course of study, it is key that the writing and evaluation of drafts are formalised for writing assessments. 
Writing interventions should not simply be resigned to the territory of English as a subject or discipline. Embedded writing practices can take place in any subject or academic space. Approaching writing as a unique and embodied learning strategy has proved instructive in the development and design of the writing-intensive course taught to first year architecture students in the SoAP at Wits.

\section{DESIGN THROUGH WRITING}

In the context of the teaching and practice of architecture, we think about writing in a number of different ways, or categories. First among these is seeing writing as communication in the broad sense. It conveys to a broader public what the world of architecture is trying to achieve and, in doing so, has the potential to break down the elitist reputation of architectural discourse and practice as belonging only to those 'in the know'. Effective communication can work to create a more discerning audience who, in turn, can participate in a debate about what constitutes a more sophisticated and successful built environment.

In the Design studio context, facility in critical literacy works to help students construct logical arguments, making them better equipped to address challenges that may arise in the design process and to communicate the ideas and concepts underpinning their designs. In the early stages of the design process, written observations encourage students to engage in a more focused way with context and engage in more complex thinking practices. The process of critical writing together with research mirrors the design process and may be used as a bridge for understanding conceptual design for first-year students.

Another way of looking at writing in an architectural and built environment context, has to do with representation. Given that architecture is as much about the 'physical object' as it is about ideas (as well as a matrix of other social and political concerns), critical literacy can be used to encourage curiosity about other aspects of architecture. Writing, by its nature is a slow and committed act, and as such, counteracts the exigencies of our fast-paced world, where speed and efficiency often come at the expense of engaging in activities that allow for sustained and thoughtful reflection. It is in this way that writing can be used as a powerful strategy to develop embodied learning and thinking.

Articulating abstract ideas to oneself is critical in the development of a design, but there are deeper parallels between writing and design. Design and language each have a set of basic functional or grammatical requirements that need to be met, but the correctly resolved result also boasts the potential to communicate significant, complex meaning, and give delight. This means that both these communicative modalities possess transformative possibilities: i.e. the 
power to transform language from correct grammar to great literature, or architecture from a functional design to a great building. Timothy Love describes 'two highly charged moments' of transition in the design process, when the practical 'problem to solve' can be 'converted into an operational strategy ... conceived of and resolved in purely architectural terms', and 'when reciprocities can be created between a series of seemingly separate but connected decisions' (Love 2006, 194).

It is not accidental that Vygotsky's constructivist theories on proximal learning and scaffolding are key concepts both in architectural studio pedagogy (Callender and Callender 2005) and in second language learning pedagogy (Gibbons 2002). Consequently, the establishment of good writing skills offers opportunities to learn and establish cognitive thinking patterns which should assist students as designers. Writing or drawing a thought forces one to refine it. The most important commonality between writing and design is that when one commits an abstract thought to paper, one can then distance oneself to critically evaluate it, to learn from this and return to improve it. This speaks to the essential role that careful and reflective critique plays in the process of design resolution, which should, with proximal development, become one with the student's own internal dialogue with herself.

The Memory Box project offers the first opportunity for an embedded writing intervention in the Design curriculum. For this project, students are required to compose a poem that reflects their sense of self, prompted by a series of concrete and tangible items built into a 'memory box' installation. Before attempting to write their poems, students engage in a number of exploratory writing activities to help them compose a reflective and thoughtful poetic response to their installation. Exploratory writing denotes '... the kind of exploratory, thinking-on-paper writing we do to discover, develop, and clarify our own ideas. Exploratory writing is typically loosely structured and tentative ....' (Bean 2011, 120).

Postgraduate tutors draw upon creative writing prompts to help students find a way in which to write through and about their experience of constructing a 'memory box', imaginatively exploring how different cadences in voice and rhythm can deliver different connotative effects as students make their way towards constructing a neatened and lyrical form of poetic expression. This promoted sensitivity to style and technique, helps to activate students' awareness to things like form, register, and audience, thus helping them realize how these three things will play an important role in terms of how they communicate their ideas and designs to a larger audience. This form of creative work easily lends itself to a practical invocation of scrapbooked or workshopped style of composition. At this particular juncture, exploratory writing thus works very well as a pedagogical tool, mostly because it emphasises 
the fact that all acts of composition designate a process of thinking that is always continually evolving and expanding. Students reported that they enjoyed working on this assignment, and despite the intensely personal nature of the poems, quite proudly elected to read their creative work - as part of their Design presentation - to the rest of their classmates.

Process or exploratory writing tasks reinforce, through practice, the recognition that writing requires multiple drafts and edits before arriving at a submission-ready version. In moving towards more critically inclined and academically rigorous approaches to writing, these exercises can help to bridge the gap between creative and analytical assessments. Writing in an exploratory manner can be used to help students develop confidence in finding a suitable academic voice through which to communicate their design concepts. Process writing tasks can then give way to low-stakes writing exercises. Low-stakes writing signifies short and nonintimidating written exercises that carry little to no mark weighting, but are still supervised by teaching assistants (i.e. tutors), who provide feedback with respect to the structure and coherency of students' expression.

An example of a low-stakes exercise used in the embedded course is précis writing. This activity not only helps to build students' note-taking skills, but also assesses the extent of their understanding. Précis writing activities present opportunities for educators to evaluate whether students are able to extract the gist of a scholarly argument and reproduce it clearly, and in their own words. With the proliferation of plagiarism becoming a perennial problem for universities around the world, it is becoming increasingly necessary to find ways to help students develop a scholarly and independent register they feel comfortable adopting. Another way of putting this into practice is by getting students to write a short analytical assessment that critically reflects on a Building Citation they have researched in the Architecture Library. Exposing students to appropriate academic material and requiring them to respond to these sources through both verbal and written means on a frequent, low-stakes basis helps to ground good academic practices.

Writing-intensive pedagogy establishes a platform from which students are persuaded to write their way to thinking, whether through exploratory or low-stakes writing. Embedded writing as an approach to learning, ultimately helps to build students' confidence, reinforcing the fact that writing is not only a product of thinking, but is also a productive process of thought.

\section{ARCHITECTURAL HISTORY AND WRITING}

While one of the main justifications for introducing a writing course for first-year architecture students was to provide them with the opportunity to develop their written and verbal 
communication skills, another and even more compelling reason was to encourage students to see writing as a vehicle through which to mature and amplify their critical thinking. Early on in his teaching at SoAP, Randall Bird observed that students treated writing as a way of simply describing or 'writing up' a collection of events or observations, rather than as a way of pursuing a deeper and more complex understanding of a topic. He noticed that students were also ill-equipped at integrating information and ideas from their own observations, alongside those gleaned from primary and secondary courses, into their own writing. Consequently, most students struggled with using sources judiciously or concisely, often allowing other people’s arguments to crowd out their own thinking.

In the year-long History course, which introduces students to a variety of architectural examples from around the globe, writing and research assignments serve to establish a common understanding of language and terminology for our students, who enter the programme from a range of educational and cultural backgrounds. One of the challenges of teaching a universitylevel architectural History course is that, in South African secondary education, the subject of History is not available at all secondary schools, and even when it is part of the curriculum, very few learners elect to take this subject through to their final year of high school matriculation. As a way of introducing students to History, lectures emphasised the importance of the social dimension of architecture and the ways in which architecture defines relationships of individuals within small groups of people and larger communities. Among the many aims of the course was to show students that the study of architecture across a variety of historical contexts allows us to extend our memory to more remote times and places, thereby allowing us to benefit not only from our current experiences, but from human epistemologies across time and space.

The History assignments are designed to reinforce the basic writing and critical thinking skills that students are learning in the Writing course. An additional benefit of adopting an intensive writing approach is that both lecturers are in close correspondence and are able to pay attention to how students are progressing with the overlapping objectives of both courses. A similar sort of integrated interaction occurred with the Design lecturer, too.

For the first History assignment, students are asked to choose a building that they can closely observe, for example, on the Wits campus or in their neighbourhood. The purpose of the assignment is to provide students with an opportunity to practice turning the visual into the verbal, which is a touchstone of all visual inquiry. Their written description consists of a vivid and intensive description of both this building's exterior and interior with attention to close, careful analysis. Students are encouraged to visit their building of choice at least three times, to 
think of the building as a three-dimensional object, and to write at least three drafts of their essay before submitting it for assessment. Students were supplied with a set of guidelines to include in their descriptions, such as: the general location of the building; measurement and proportion; its general structural system; materials used; the building's architectural language; linear qualities; geometries; spatial qualities; the relationship between the building's interior spaces and exterior; colour; light; sensory impressions; function; and experiential qualities as one walks around and through a building.

In the Writing course, students are given assistance with their first History assignment. This includes providing systematic guidance with good writing practices and conventions relating to sound academic form: namely, unpacking the assignment brief, identifying instruction words, and reading the wording of the brief in context against those instructions; how to adopt appropriate style and academic register; organising ideas according to an academic essay structure, as well as the crafting of a clear thesis statement. Multiple revision workshops are convened where the importance of drafting, revising, and editing the written word is stressed via practical reinforcement. These workshops also encompass the teaching and rehearsing of correct referencing methods, which include tips on how students should contextualise and integrate quotations into the flow of their own arguments.

\section{WRITING AND 'READING THE CITY'}

The embedded Writing course's content and mode of delivery differs between the first and second quarter. In the first quarter, the themes and concerns are derived from the first year Design Studio and History course. In this way, the writing-intensive activities and exercises neatly dovetail with the topics covered in the Design and History curriculums. This integrated approach helps to embed the writing within architecturally foregrounded projects and assignments.

In the second quarter, the component's approach and delivery shifts. Called 'Reading the City', students receive a course pack that contains a selection of cross-genre city readings. The pack consists of poems, documentary texts, essays, short stories, excerpts from novels and journal articles. All readings place their focus on the city of Johannesburg. Students are required to read, engage, and write their own literary based representations of the city during this quarter. The disciplinary foundation of this section of the course takes it cue from the crossover field between urban studies and literature. In the provided readings, students are exposed to a different mode of constructing and packaging mediations of the built environment. Since candidate architects are usually visually and graphically literate, introducing architecture 
students to alternative ways of approaching and articulating space through literary representations helps them become more conversant with a different critical vocabulary and spatial modality.

To briefly expand on the rationale behind using literary texts as a vehicle through which to develop students' critical literacy, it can be said that the teaching of literature provides a constructive platform from which to engage students in embedded reading and writingintensive activities. Moreover, the study of literature encourages students to engage critically with the world by exposing them to different perspectives, requiring them to consider contexts and subject positions with which they may be unfamiliar. In this way literature provides students with opportunities to encounter various aspects of the built environment through the imaginatively explorative frontiers of the literary realm.

One of the prescribed texts is a selection from Phaswane Mpe's 'walkerly' novel, Welcome to our Hillbrow (Mpe 2001). The first chapter, 'The Map', is reproduced in the reading pack and during lectures is analysed in terms Michel De Certeau's theory of 'walking the city' (De Certeau 1984) and Walter Benjamin's inscription of flânerie (Benjamin 1999). In 2013, we arranged a walking tour of Braamfontein, mimicking-in-reverse the route the protagonist of Mpe's text takes through Hillbrow on his way to the Wits University campus. This transposing of physical city into literary space helps students conceptualise and understand the hermeneutics of the mapping process canvassed by the accompanying critical theory. Students are then set the task of creating their own personal map of the city. This map needs to be a subjective rendering of city space and requires students not only to metaphorise how they individually perceive the city as a material entity, but also calls for a psychic or mental transference of space (i.e. how they inhabit it figuratively as an 'inner map'). Students are asked to write a critical accompaniment to their pictorial spatial representation. This exercise explicitly requires students to transliterate their creative interpretation of the visual spectrum to the linguistic. Students need to methodically explain the symbols, legends, and ideas behind the graphic work. This exercise is important as it forces students through the confines of a short critical essay to communicate the map to an audience through words only. Their critical piece must also carefully articulate what their graphic choices say about their own personal interpretation of Johannesburg. They must substantiate why certain features of the urban environment feature more prominently in their map and why other aspects have been eclipsed. In doing so, students are asked to reflect critically on their own subjective inhabitation of space.

Each week's reading is accompanied by a thematically linked written exercise, which is completed during tutorials. The poetry complement consists of Johannesburg-themed poems, 
such as Mongane Wally Serote’s 'City Johannesburg' (Chapman 1986, 166-67), William Plomer’s 'Johannesburg' (Chapman 1986, 88-89), and Lionel Abrahams’s 'The Fall of Van Eck House' (1988, 40-41) and 'Thoughts on Johannesburg’s Centenary' (Abrahams 2010, 1315). After reading Serote and Plomer's poetic representations of the city, students have to respond by writing a Johannesburg-inspired concrete poem. Through the marriage of form and content, students have to compose a poem in the shape of something that correlates with the chosen subject matter.

In another exercise, students write their own city-portrait imitating Ivan Vladislavić's experimental style in 'Street Addresses' (1998, 305-313). This is a text that exhibits a literary kind of spatial awareness, illustrating a sensitivity to the visual and concrete facets of urban life; it is for this reason that this particular text is used as an instructive bridge, transporting architecture students from the visual to the literary. 'Street Addresses' could be described as the linguistic equivalent of a photographic 'snapshot' of urban life or experience. Students approach this exercise by taking the idea of a photographic frame as the inspiration for their own short piece about the city.

To expose students to different media and genres, Neill Blomkamp's film, District 9 (2009), is screened. In both the lecture and the tutorial sessions, students are engaged in a discussion around futuristic urban typologies. Students are asked to evaluate Blomkamp’s allegorical rendering of Johannesburg as a contemporary dystopian space. In response to the film, students write an opinion piece that considers District 9's depiction of Johannesburg as a dystopian space of 'othering' and alienation, as a means by which they can reflect on their own experiences of alterity in the metropolis.

As part of the main instrument of assessment for the second quarter's Writing course, students submit a critical essay at the end of the semester. Writing essays helps students to construct a logical line of argumentation by training them to substantiate their ideas clearly and cogently in a sustained and rigorous way. The assignment brief calls on students to consider the ways in which they have been shaped by the city. It requires students to reflect critically on the urban representations they have been exposed to during the second quarter, and in doing so, requests that they juxtapose these modes of representation against their experience of the material reality of the city of Johannesburg.

In concurring with the findings of Richard Hoag and David Smit in their paper. 'Writing in Design Studio' (2014), architecture students need to be taught how to seek appropriate evidence to support their claims in order to produce coherent and cogent writing. In speaking to the four taxonomies of writing as outlined by James Kinneavy in A Theory of Discourse, 
Hoag and Smit claim that architects, when writing for clients or colleagues, primarily devote their time to 'argumentative' writing (2014, 93). The locating of evidentiary support in prescribed literary texts to substantiate a claim made in an academic essay can be seen as a helpful and constructive technique in developing competence in argumentative writing. Once successfully learnt and practiced, this type of argumentative writing can be used later in their degree and after they have qualified. The type of close reading and locating of evidentiary support proffered by critiquing literary texts turns out to be a useful and transferable skill, relatable to different disciplines and professional environments.

Unfortunately, this essay is where we find the students' facility of expression and degree of critical competence failing them. First-year architecture students are quite comfortable writing creative exercises and short reflections, but when it comes to writing a sustained, academically structured argument, they fare poorly. This partly stems from the fact that students do not manage their time effectively, prioritising their Design projects over other assessment deliverables, thus tending to throw their Writing course assignment together a few days before the deadline. Furthermore, and linked to the preceding problem, they do not commit to revising their work through the writing and rewriting of multiple drafts (despite the benefits of process writing taught early on in the year and in the History course). In the lecturers' and tutors' experience of marking these essays, architecture students seem to think they need to sell their essay to their reader and so employ reductive and unnecessarily facile statements, which frequently fail to substantiate or persuasively motivate (often bold) claims. Going forward, the structure of the curriculum will need to be adjusted to accommodate a stricter and more formalised plan requiring students to write, re-write, and revise essay drafts in preparation of the submission deadline. Tutors will then be afforded the opportunity to work through poorly structured preparatory work in conjunction with students in order to guide them through the slow stages of crafting critically coherent and carefully substantiated written work.

\section{VALUE OF THE EMBEDDED WRITING COURSE}

As is the case with most architecture students around the globe, there is a perception that Design takes priority over other courses. The challenge in teaching writing-intensive pedagogy to BAS students is to convince them to buy into the value of critical writing for their development as future architectural designers. In spite of this obstacle, at the end of the first semester, it appeared as though writing-intensive approaches to learning enjoyed currency amongst the students, who reflected in their feedback that they witnessed an improvement in their ability to think and write critically over the course of this semester-long intervention. A few students 
even requested a continuation of the Writing course into the second semester. The key ingredient for this success is the use of intellectually challenging and thought-provoking architectural subject matter in the embedded critical reading and writing exercises, which makes these writing-intensive sessions relevant to even the most skilled writers. At the same time, students who require foundational instruction in writing skills receive this support in the form of constructive, individual feedback, without this needing to become the focus of the course, or being obvious to their peers.

There was a marked improvement in the standard of essay writing after engaging with these writing-based interventions. In the ARPL1000 student questionnaire responses (Janse van Rensburg 2015), the following common concern, 'I did not understand project briefs at all', disappeared after the introduction of the critical Writing course. The course's greatest value lies in all students' real intellectual development, particularly in relation to the acquisition of competence in dominant literacy skills, which enables students to find their own academic voice and confidence. This development has permeated into more diverse choices for research topics and has eventually resulted in an improvement in the quality of critical discourse in Masters' dissertations.

\section{CONCLUSION}

This article considers the success of the writing-based interventions that were integrated into the SoAP first-year Design Studio and History of Architecture course at Wits University. In ensuring that students are able to communicate their ideas and drawings precisely and clearly through graphic, verbal, and written mechanisms, this intervention contributes towards the development of a crucially important skill-set necessary for future architecture professionals. Embedded writing boosts students' confidence in their ability to think independently and critically. This kind of foundational pedagogical support helps to ground successful and effective learning habits, thereby motivating students to pursue further study in the academy. Some critics may argue that privileging academic standards in a top-down fashion, represent a 'colonial' imposition of knowledge, forcing students to write in a specific fashion according to a set of 'established' rules. Being fully aware of the validity of this sort of criticism, the teaching of intensive writing facilitates the generation of students' own academic voices, which are communicated with clarity and articulated with cogent, critically motivated ideas. 'Enunciation' is a fundamental concept in decolonial epistemology. Mignolo describes the decolonial as 'a world that is constantly invented in the enunciation' (Gaztambide-Fernandez 2014, 198). Facilitating students' ability to express their individual worlds in writing, provides 
them with the tools to become co-creators of a meaningfully decolonised society.

\section{NOTES}

1. Bloom's taxonomy of learning defines a pyramid of modalities of learning, from the most concrete at the base to the most conceptual at the top, i.e. remembering, understanding, applying, analyzing, synthesizing, and evaluating. Design and critical writing demand learning modalities at the apex of this pyramid

2. According to Bourdieu every social grouping or field (e.g. Architecture) has a distinct and differentiating preferred culture (habitus). An individual who can display this culture has 'cultural capital'; leaders have high cultural capital. The space in which this group practices this culture is its 'habitus', and the accepted discourse within this field is its 'doxa'. The person who espouses a view outside the doxa will be ignored or shunned into toeing the line, an often unspoken process described as 'symbolic violence'.

3. This section is adapted from 'Enabling Transformation - A Model for Facilitating Successful Design Learning Outcomes in First Year Bachelor of Architectural Studies' (Janse van Rensburg 2015).

4. The concepts of hidden (internalised) dominance and oppression originate from Paolo Freire's critical social theory, which postulates that the oppressed eventually construct their own identity along the lines of inferiority and subservience dictated by those in power, and the dominant construct their identity as being superior and view this comfortable perspective as being neutral. This becomes a self-perpetuating system when people assume these false identities, deeply affecting self-perceptions, aspirations and communication.

\section{REFERENCES}

Abrahams, Lionel. 1988. Lionel Abrahams: A Reader, edited by Patrick Cullinan, 40-41. Johannesburg: AD Donker.

Abrahams, Lionel. 2010. 'Thoughts on Johannesburg's Centenary (while by the Jukskei River at Broederstroom)'. In From Jo'burg to Jozi, ed. Heidi Holland and Adam Roberts, 13-15. Johannesburg: Penguin.

Bean, J. C. 2011. Engaging ideas. San Francisco: Jossey-Bass.

Benjamin, Walter. 1999. The Arcades Project, translated by Howard Eiland and Kevin McLaughlin. Cambridge (Ма.): The Belknap Press.

Blomkamp, Neill. (Dir.). 2009. District 9. Film. USA: Tristar Pictures and Wingnut Films et al.

Bloom, B. S., M. D. Engelhart, E. J. Furst, W. H. Hill and D. R. Krathwohl. 1956. Taxonomy of educational objectives: The classification of educational goals. Handbook I: Cognitive domain. New York: David McKay Company.

Bourdieu, Pierre. 1977. Outline of a theory of practice. Cambridge: Cambridge University Press.

Bourdieu, Pierre and Jean Claude Passeron. 1990. Reproduction in education, society and culture, vol. 2. Theory, Culture \& Society. London: Sage.

Callender, Janssen and Stacey Callender. 2005. 'Constructing passages: Accommodations for diverse learners in architectural education'. Paper presented at A Beginner's Mind, 21st National Conference on the Beginning Design Student, University of Texas, San Antonio. http://novicedesign.org/NCBDS/21/pdf/08_ConstructingPassages.pdf (accessed 22 September 2014).

Chapman, Michael (Ed.). 1986. The paperbook of South African Poetry. Johannesburg: AD Donker.

City, Elizabeth A., R. E. Elmore, S. E. Fiarman and L. Teitel. 2009. Instructional rounds in education: A network approach to improving teaching and learning. Cambridge, Mass.: Harvard Education Press. 
Clegg, Sue. 2011. 'Cultural capital and agency: Connecting critique and curriculum in higher education.' British Journal of Sociology of Education 32: 93-108.

Council on Higher Education. 2010. 'Access and throughput in South African higher education - Three case studies.' In Higher Education Monitor 9. http://www.che.ac.za/media_and_publications/ higher-education-monitor/higher-education-monitor-9-access-and-throughput (accessed 23 August 2011).

De Certeau, Michel. 1984. The practice of everyday life, translated by Steven Randall. Berkley: University of California Press.

Emig, Janet. 1977. 'Writing as a mode of learning'. College Composition and Communication 28(2): 122-128.

Freire, Paolo. 1990. The pedagogy of the oppressed. London: Penguin Books Ltd.

Gaztambide-Fernández, Rubén. 2014. 'Decolonial options and artstic/aestheSic entanglements: An interview with Walter Mignolo.' Decolonization: Indegeneity. Education \& Society 3(1): 198.

Gibbons, Pauline. 2002. Scaffolding language, scaffolding learning: Teaching second language learners in the mainstream classroom. Portsmouth, NH: Heinemann.

Hoag, Richard L. and David W. Smit. 2009. 'Writing in Design Studio', 93-98. Paper presented at We Are a Discipline. $25^{\text {th }}$ National Conference on the Beginning Design Student, College of Art and Design, Louisiana State University, March 12-14.

Janks, Hilary. 2010. Literacy and power (Language, Culture and Teaching Series). New York, London: Routledge.

Janse van Rensburg, Ariane. 2012. 'Questionnaire on ARPL1000. Distributed to students who had completed the course between 2007 and 2011', on-line questionnaire. Unpublished Material, August 2012.

Janse van Rensburg, Ariane. 2015. 'Enabling transformation - A model for facilitating successful design learning outcomes in first year Bachelor of Architectural studies'. PhD dissertation, University of the Witwatersrand.

Love, Timothy. 2006. 'A Minor Theory of Architecture - An Argument for Focusing (Again) on the Specific Architectural Operation.' Paper presented at Intersections, the 22nd National Conference on the Beginning Design Student, Iowa. http://novicedesign.org/NCBDS/22/22.html (accessed 6 October 2014.

Menary, Richard. 2007. 'Writing as thinking'. Language Sciences 29: 621-632.

Mpe, Phaswane. 2001. Welcome to Our Hillbrow. Pietermaritzburg: University of Natal Press.

Olweny, Mark R. O. 2013. 'Socialisation in Architecture Education.' AAE, 2013. http://architecturaleducators.wordpress.com/http://architecturaleducators.files.wordpress.com/20 13/12/olweny-2013-socialisation-in-architectural-education.pdfconference-2013/conference2013-papers/ (accessed 24 September 2014).

Plomer, William. 1986. 'Johannesburg.' In The paperbook of South African English Poetry, ed. M. Chapman, 88-89. Johannesburg: AD Donker.

Schön, Donald A. 1983. The reflective practitioner: How professionals think in action. 80. New York: Basic.

Serote, Mongane Wally. 1986. 'City Johannesburg.' In The paperbook of South African English Poetry, ed. M. Chapman, 166-167. Johannesburg: AD Donker.

Vladislavić, Ivan. 1998. 'Street addresses.' In blank_Architecture, Apartheid and After, ed. Hilton Judin and Ivan Vladislavić, 305-313. NAI Publishers: Rotterdam.

Wendl, Nora. 2009. 'Scratching the Tabula Rasa: Writing toward building'. Paper presented at We Are a Discipline, $25^{\text {th }}$ National Conference on the Beginning Design Student. 12-14 March, College of Art and Design, Louisiana State University. 